\title{
Development and Testing of the Healthy Food Pantry Assessment Tool
}

\author{
Alexandra Bush-Kaufman, $\mathrm{MPH}, \mathrm{RDN}^{1,2}$; Karen Barale, MS, $\mathrm{RD}^{1,2}$; \\ M. Catalina Aragón, $\mathrm{MS}^{1,2}$; Marie Walsh, $\mathrm{MPH}^{2,3}$
}

\begin{abstract}
Objective: To develop and test an observational survey that quantifies food pantry environments (FPE). Design: Best practices in FPE were identified through key informant interviews. The tool was pilot-tested, including a content review, and then field-tested for reliability.

Setting: Key informant phone interviews $(n=41)$; pilot and field test visits occurred at 45 pantries from multiple states.

Subjects: Food bank/pantry staff and nutrition educators were recruited for interviews through purposive and snowball sampling. Pilot and field test survey users $(n=65)$ were food pantry representatives and matched community partners who both rated the FPE using the tool.

Variables Measured: Pearson correlation was used to determine test-retest and interrater reliability.

Analysis: Qualitative data were coded for healthy FPE strategies. Quantitative data were calculated using descriptive statistics (significant at $P<.05$ ).

Results: Qualitative data were coded for observable FPE characteristics. Reliability scores were substantial to nearly perfect for 48 of 61 survey items (79\%) for test-retest and 49 of $61(80 \%)$ for interrater reliability (Pearson $r=.6-1.0)$.

Conclusions and Implications: The Healthy Food Pantry Assessment Tool is research-tested and can be used to evaluate and quantify the healthfulness of FPE.

Key Words: Built environment, food assistance programs, food insecurity, healthy places (J Nutr Educ Behav. 2019; 51:578-588.)

Accepted October 8, 2018. Published online December 6, 2018.
\end{abstract}

\section{INTRODUCTION}

In 2016, 15.6 million American households (12.3\%) reported experiencing food insecurity during the previous 12 months. ${ }^{1}$ A 2014 Feeding America study reported that food assistance programs (food banks and food pantries) were serving approximately 46.5 million low-income people per year, including 12 million children and 7 million seniors. ${ }^{2}$ Earlier reports showed that adults from food-insecure households had a 21\% higher risk for clinical hypertension and a 50\% higher risk for diabetes compared with adults in food-secure households. ${ }^{3}$ Current trends demonstrated that households are using private food assistance, including pantries and hot meal sites, to cope with chronic household food shortages. ${ }^{4,5}$ Food pantries were estimated to provide up to $25 \%$ of the total monthly food supply in low-income Americans' monthly diets. ${ }^{6}$ Cross-sectional data reflected a lower diet quality available from private food assistance to Americans accessing this food source. ${ }^{7,8}$ Foods offered at food pantries have a

\footnotetext{
${ }^{1}$ Washington State University-Extension, Pierce County, Tacoma, WA

${ }^{2}$ Regional Nutrition Education and Obesity Prevention Center of Excellence-West, Fort Collins, $\mathrm{CO}$

${ }^{3}$ Larimer County Human Services, Fort Collins, CO

Conflict of Interest Disclosure: The authors have not stated any conflicts of interest.

Address for correspondence: Alexandra Bush-Kaufman, MPH, RDN, Washington State University-Extension, Youth and Families Unit, Pierce County, 3602 Pacific Ave, Ste 200, Tacoma, WA 98418; Phone: (253) 798-3253; Fax: (253) 798-3165; E-mail:

alexandra.kaufman@wsu.edu

Published by Elsevier Inc. on behalf of Society for Nutrition Education and Behavior.

reputation for being highly processed, high in sodium and fat, and shelf stable. These foods do not meet the recommendations of the 2015 Dietary Guidelines for Americans ${ }^{9}$ and generally do not promote health in pantry clients. Food assistance agencies have a growing demand for nutrient-dense foods such as fruits, vegetables, and lean protein ${ }^{10,11}$ because low-income Americans have limited purchasing power to acquire adequate amounts of these healthy foods. ${ }^{12-14}$

Dietary patterns of communities and individuals are influenced by their food environments. ${ }^{15-17}$ Healthy food environments have proven difficult to access for low-income Americans, those living in rural areas, ${ }^{18,19}$ and racial minorities, which contributes to growing disparities in health. ${ }^{20}$ Food pantries offer a venue for comprehensive ecological change that may improve the diets of low-income Americans. $^{21}$ However, the stigma of accessing a food pantry or governmental nutrition assistance is known to prevent use of these resources to reduce 


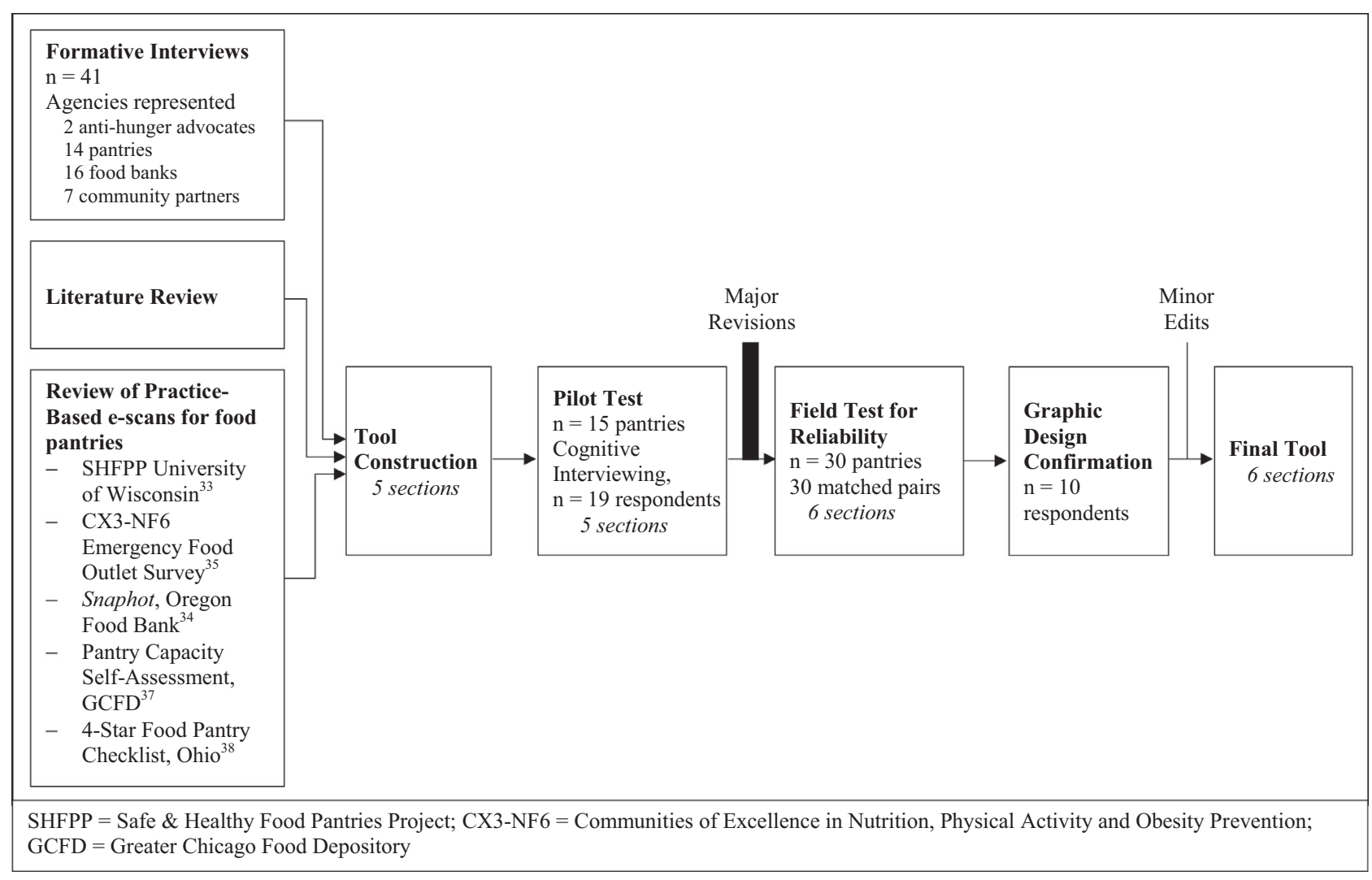

Figure. Overview of the development and testing of the Healthy Food Pantry Assessment Tool.

food insecurity. ${ }^{18,22,23}$ Interpersonal relationships among pantry clients, volunteers, and staff have a role in addressing community food security. ${ }^{24}$ Pantry clients may be considered vulnerable consumers because they experience food insecurity and actively seek food resources to address this dilemma. ${ }^{25}$ Therefore, the emotional environment, or how individuals are treated within the physical space, may affect the use of pantry foods by potential clients. For example, a designated waiting area that is only outdoors (emotional environment) can affect the likelihood that clients will access food assistance when needed. ${ }^{24}$ Previous interventions in pantry settings include client empowerment and the use of client choice models to encourage healthy behaviors and increase dignity while receiving food assistance. ${ }^{4,26}$ Evidence illustrated how environmental interventions based on behavioral economic theory can influence diet quality $^{27}$ and be employed within food assistance settings. $^{25,28}$ Assessment tools (e-scans) were created to evaluate food environments in food retail stores, restaurants, schools, worksites, and homes. ${ }^{29-32}$ The usefulness of such tools is limited by their validity and reliability. At the initiation of this study, food pantry environmental (FPE) assessment tools were emerging from unscored tools or formative evaluations that were state-specific. ${ }^{33-36}$ The purposes of this study were to develop a quantified observational survey of the physical and emotional environment that was appropriate for diverse food pantry settings, and to test the tool's reliability among distinct users.

\section{METHODS}

The development and testing of the Healthy Food Pantry Assessment Tool (HFPAT) involved multiple phases: (1) formative interviews and review of evidence, (2) tool construction, (3) pilot test, (4) field test for reliability; and (5) graphic design confirmation (Figure). ${ }^{33-35,37,38}$ The initial scope of this project was Alaska, Arizona, California, Colorado, Hawaii, Idaho, Montana, Nevada, New Mex- ico, Oregon, Utah, Washington, and Wyoming, referred to here as the National Institutes of Food and Agriculture (NIFA) western region. Sites in Delaware, Maryland, and New Hampshire were added for reliability testing.

\section{Formative Interviews and Review of Evidence}

The researchers conducted in-depth, semi-structured interviews to investigate ongoing strategies to improve the healthfulness of food assistance settings. Respondents were recruited through purposive and snowball sampling. Food banks and pantries in the NIFA western region were identified through an Internet search and potential respondents were contacted (purposive sampling). Those who agreed to be interviewed were recruited as key informants; they were interviewed and then asked to refer other potential contacts in the food assistance system (snowball sampling). The formative interview questions were cognitively tested with a sample of comparable key 
informants who were outside the geographic NIFA western region. Trained research coordinators conducted all cognitive $(n=9)$ and indepth $(n=41)$ phone interviews. Interview questions explored how respondents defined a healthy FPE and strategies or actions taken to achieve these descriptions. Interviews were audio-recorded, transcribed verbatim, and entered into ATLAS.ti software (version 7, ATLAS.ti Scientific Software Development GmbH; Berlin, Germany, 2013). A codebook was developed by the interviewer and first author $(\mathrm{ABK})$ from interview notes and emergent topics. Then, 5 transcripts were coded following an in vivo approach and edits were made to the codebook until > 80\% agreement regarding codes was reached. A third research assistant double-coded interviews with the interviewer to establish intercoder agreement, calculated by a kappa $(\kappa)$ of 0.77 including code overlap $^{39}$ and $72 \%$ agreement regarding code assignments. Once coder agreement was established, the interviewer (primary coder) coded 25 interviews and the research assistant (secondary coder) completed 16 interviews, respectively. Thematic content analysis of interview transcripts was conducted in an exploratory and emergent design ${ }^{40,41}$ because there were no preselected best practices for healthy food pantries that interviewers were investigating. Analysis aimed to elucidate observable characteristics of a healthy FPE. At the same time as the in-depth interviews, 3 researchers examined peer-reviewed and gray literature on interventions in food assistance settings. Environmental scans or observational surveys (Figure) used to assess food pantries were analyzed for common traits. Topics represented in all 3 areas of this triangulation were included as draft questions in the pilot survey tool.

\section{Tool Construction}

The content, format, and layout of the tool were established in phase 2 . Results from the formative interviews were compared with e-scans in practice and research literature. The formatting of the tool reflected other pantry e-scans in practice. ${ }^{33-35}$ Visual elements recommended by Dillman et $\mathrm{al}^{42}$ were used to design the layout and structure of questions and responses. Questions were grouped according to observable characteristics of the FPE. Alike items were grouped together and ordered in such a way that the survey could be completed during a tour of the food pantry (ie, beginning with the entrance and ending in the food storage area). The HFPAT was intended for use by food assistance agency staff and volunteers, with community nutrition education partners as secondary users. The initial pilot tool had 5 sections and 63 questions, 13 of which were unscored.

\section{Pilot Test}

Content review and face validity were achieved by pilot-testing the tool with food pantry representatives. Pilot tests included site visits and cognitive interviews with a sample of pantry representatives to assess the content, wording, response options, and graphic design of the tool. A convenience sample of pilot test sites $(\mathrm{n}=15)$ across 5 states (California, Colorado, Nevada, Oregon, and Wyoming) were selected through recruitment and referrals by key informants from phase 1 . The HFPAT was completed by a representative of the participating pantry and the visiting researcher (ABK). Cognitive interviews ( $n=19$ respondents) were conducted immediately after completion of the HFPAT, lasted 30 -90 minutes, and were audiorecorded and transcribed. Content review was carried out by investigating each question's relevance and whether respondents agreed that each item reflected an improvement in the pantry's physical and emotional environment. Face validity was pursued by question probes that elucidated pilot-testers' interpretations of question items and survey graphic design. A standard form was used to record the internal rater's score to the visiting (external) rater's score and to note the differences; cognitive questions investigated how the internal rater decided on the selection and collected feedback for improvements to face validity. If $>2$ internal pilot testers recommended changes, these changes were made and tested in the next iteration of the pilot survey. All participating pilot test sites were offered a grocery gift card to thank them for their time. When the pilot tests concluded, a social science research center, the Washington State University Social and Economic Sciences Research Center, reviewed the HFPAT for face validity and readability.

\section{Field Test for Reliability}

Based on the results from the pilot test, the field test was designed to assess the reliability of the HFPAT across distinct users. The field test tool included 72 items (52 scored and 20 unscored). Pantry representatives were recruited by their community partners from local Supplemental Nutrition Assistance Program-Education (SNAP-Ed) and/or Expanded Food and Nutrition Education Program (EFNEP) staff, forming dyads. A convenience sample of food pantries participated in the field tests from 7 states: California, Delaware, Maryland, Montana, New Hampshire, New Mexico, and Washington. Participating pantries $(\mathrm{n}=33$ sites) received the instruction guide, implementation logs, and prestamped, preaddressed envelopes to return the surveys. A 2-hour webinar training on using the HFPAT was required at the initiation of the field test for all participants. Dyads were not required to implement FPE intervention strategies to receive the incentives. Initial assessments were completed by 30 dyads, because 3 pantries withdrew after the training owing to limited staff capacity. The field test was conducted from October, 2016 through August, 2017 and included 30 food pantry agencies and 50 raters. Community partners often matched themselves with their food pantry sites as part of a large program intervention and multiple sites were rated by the same community partner; 2 raters scored 2 pantries each and 4 raters scored 3 pantries each. Test-retest reliability was assessed by evaluating the level of agreement between repeated HFPAT assessments within a 7 - to 14 -day period. ${ }^{43}$ Dyads, described earlier, were asked to meet at the pantry setting and complete the HFPAT individually. Then, they returned the HFPAT surveys (survey 
1) and scheduled a second meeting within 7-14 days. The dyad individually completed the HFPAT again during the second meeting (survey 2). Dyads were asked to complete surveys 1 and 2 in the same month, because many food pantries experienced monthly fluctuations in donations, volunteers, and funding. They were asked not to communicate with each other until survey 2 was completed and mailed back. Some pantries did not change their offerings of food within a month and there was trait consistency. This warranted a survey that was reliable regarding how measures were scored across time points by the same user. Test-retest reliability was calculated for each item using Pearson correlation, $r$. Interrater reliability was calculated by 2 methods: (1) between the 2 raters for the entire survey using only survey 1 and intraclass correlation coefficients (ICC) for numeric data ${ }^{44}$ and Cohen's $\kappa$ for binary items; ${ }^{45}$ and (2) using Pearson correlation, $r$, to assess agreement for unique raters across different settings between raters at surveys 1 and 2 . Significance was established as $P<.05$ and relative agreement between scores of individual items was interpreted with the following classification scales for the coefficient: 0.0 $-0.20=$ poor; $\quad 0.21-0.40=$ fair; $\quad 0.41$ $-0.60=$ moderate; $\quad 0.61-0.8=$ substantial; and $0.81-1.00=$ nearly perfect. ${ }^{46}$ Characteristics of the test sites, descriptive statistics, and ICC comparing survey 1 for interrater reliability were analyzed with IBM SPSS software (version 22, IBM Corporation, Somers, NY, 2017). R Statistical Software was used for the data analysis of Pearson correlations for each survey item (R Core Group, Vienna, Austria; 2018).

\section{Graphic Design Confirmation}

Implementation logs and preliminary data from the field test indicated a need to address the graphic design of skip logic questions. A subsample of field test respondents, both community partners and food pantries, was recruited to provide additional comments about the field draft of the tool. Cognitive interviews were conducted until saturation was reached when all respondents interpreted the graphic design and survey question similarly. A second member of the Washington State University Social and Economic Sciences Research Center reviewed the HFPAT for face validity and readability during the final editing process. The study phases were deemed exempt by the Institutional Review Board of Washington State University.

\section{RESULTS}

The HFPAT was designed to measure the physical and emotional characteristics of healthy pantry environments including aspects of accessibility, maintenance of dignity, and food safety and storage. Its largest section was designed to assess the variety, quality, and promotion of healthy foods.

\section{Formative Interviews and Review of Evidence}

Key informants self-identified as working at a local food pantry $(n=14)$ or food bank distribution agency $(n=16)$ or as a community partner of a pantry or bank $(n=7)$ or anti-hunger advocate $(n=2)$, representing both urban and rural areas. Broadly, key informants defined a healthy pantry as one that offered healthy foods (primarily fruits and vegetables [FV]) in a variety of distribution methods, provided supportive services, presented opportunities for nutrition education, and treated clients and volunteers in a respectful, dignified manner. Strategies undertaken to achieve these descriptions were grouped into 3 code families: food distribution methods, food procurement methods, and strategies in place at the pantry. Aspects of a healthy FPE aligned with 2 environmental approaches identified in the literature review: behavioral economics in nutrition education ${ }^{47}$ and the social ecological model of food and physical behaviors. ${ }^{17,47}$ These models were selected as the underlying framework for the construction of the pilot tool.

\section{Tool Construction}

Because the survey would assess the physical pantry environment, strategies in place were the focus of question item development. Observable outcomes of food procurement were the variety and quality of foods available at the pantry. The remaining survey questions were based on food distribution methods, services offered (including nutrition education), and a culture of respect and dignity. The greatest overlap in the triangulation were themes of ensuring food pantry clients access to FV and the respect and dignity of clients. Survey scoring was designed to award points that aligned with these 2 themes. Characteristics of a healthy pantry that were measured in each section were designed to reflect dignity, which was determined by how similar a pantry experience was to a shopping experience. For example, wait time and location were assessed in Section A: Location and Entrance, where waiting indoors and for less time was awarded a higher score than a pantry that had waiting areas only outside or for $>30$ minutes. The tool was designed to be administered using a paper and pencil. The HFPAT included a section to report pantry features such as pounds of food distributed, number of monthly clients, and type of food pantry (mobile, school, or neither). Section A: Pantry Location and Entrance included questions addressing walkability, ${ }^{48}$ public transit access, ${ }^{37}$ curb appeal and safety, ${ }^{49}$ and check-in or wait time. Section B: Food Available to Clients was the largest section. Priority was given to variety and quality of $\mathrm{FV}$, reflecting formative interview themes. Placement and promotion of FV were evaluated. Items referring to the quality of fresh FV were adapted from the CX3 Tier 2-Food Availability and Marketing Survey. ${ }^{48}$ Section C: Policies of the Food Pantry assessed the institutionalization of nutrition standards for foods brought into the pantry and foods distributed to clients. Two items evaluated whether food safety training was required for pantry staff or volunteers. $^{33,37}$ Section D: Frozen-Chilled -Dry Storage assessed handwashing; ${ }^{33}$ temperature ranges for frozen, chilled, and dry storage; ${ }^{33}$ cleanliness of the food receiving area; ${ }^{50}$ and chilled transportation availability. ${ }^{51}$ Section E: Services and Supplementary Programs contained 3 scored 
and 6 unscored items. The scored items were nutrition education, food demonstrations or recipes, and referrals to other social services. Unscored items unique to each agency's financial capacity and community support included backpack programs, federal child nutrition program participation, Registered Dietitian partnership, off-site pantry program, home delivery of foods, and provision of hot meals on-site. These supplementary programs were frequently reported in the formative interviews as methods food banks and pantries pursued to improve their clients' health. These items were not scored because they fell outside the physical and emotional environment. Question responses were either dichotomous (yes/no) or on a 3- or 4-point Likert scale that was used in unscored e-scans and similar tools reported in practice. $^{33,35,49}$

\section{Pilot Test Results}

The iterative process of testing each draft of the pilot tool resulted in 3 survey drafts being tested by 5 internal raters. Pilot testing continued until $<2$ edits were recommended for each question when there was disagreement regarding response selection between the pantry representative and visiting researcher. Two items were removed because pilot-testers reported that the items were not relevant to the environment: cubic chilled/frozen food storage and food bank inventory system. The question assessing the check-in procedure was divided into 2 questions reflecting the widespread practice of reducing paperwork burden for returning clients. Other changes included grouping questions according to respondent interpretation of like items; repeating scale descriptions; adding subtotal boxes for each page; and adding examples of protein, dairy, and grain foods. Section E was divided into 2 sections by scored or unscored items, which generated Section F: Supplementary Programs, which was tested in phase 4. Unscored items of Section F were dichotomous. Feedback from the first 5 pilot test visits indicated a need for detailed instructions to help users complete the tool effectively. An instruction guide was created and provided to the remaining 10 pilot test participants before their scheduled visit. The field test tool was edited from pilot test results to contain 71 questions in 6 sections, 19 of which were unscored.

\section{Reliability Results}

Table 1 lists the characteristics of participating food pantries. Tables 2 and 3 describe the results of testretest and interrater reliability by question item and survey section. Field testers anecdotally reported that the survey took 30-90 minutes to complete, depending on whether the pantry was currently serving clients. Kappa ranged from 0.53 to 1.00 and ICC was excellent (0.99 to 1.00) both for complete survey comparison, all significant at $P<.05 .{ }^{46}$ Correlations were calculated for the 52 scored HFPAT items within sections $\mathrm{A}-\mathrm{E}$ and the 9 unscored items in section F. Two correlations were not significant for test-retest reliability: fresh fruit quality, $r=.19(P=.26)$ and temperature in dry storage, $r=.16$
$(P=.79)$. Most questions (48 of 61 ) had substantial to nearly perfect testretest reliability indicated by $r>.61$ and 8 items had moderate test-retest reliability with $r=.41$ to $.60 .{ }^{46}$ Frozen lean protein variety and pest management had poor to fair correlations for test-retest reliability. Most items (49 of 61) had substantial to nearly perfect interrater reliability indicated by $r>.61$ and 7 items had moderate interrater reliability as indicated by $r=.41$ to .60 . All items in section $\mathrm{F}$ (Table 3) had substantial test-retest and interrater reliability, measured by Pearson $r$. The following 5 items had poor to fair interrater reliability: (building) visual appeal, $r=.28$ $(P=.01)$; frozen lean protein quality, $r=.34(P \leq .01)$; quality of canned foods, $r=.26(P \leq .05)$; cleanliness, $r=.24(P \leq .05)$; and pest management, $r=.38(P \leq .001)$. The scales for fresh FV quality were revised to reflect similar scales for FV variety. Low reliability of temperature in dry storage was attributed to the failure of skip logic. The question regarding pests was removed because it also had poor interrater reliability. The

Table 1. Participating Food Pantry Agency Characteristics $(n=30)$

\section{Characteristic}

Type of pantry

Single building, brick and mortar

Mobile, trailer, or recreational vehicle unit

School

Urbanicity

Rural

Urban

Open, $\mathrm{d} / \mathrm{mo}$

$\leq 10$

$11-17$

$\geq 18$

Average pounds of food distributed per $\mathrm{mo}^{\mathrm{a}}$

$\leq 3,000$

$3,001-30,000$

$\geq 30,001$

Average clients served per mo

$\leq 100$

$101-500$

$\geq 501$
Frequency (\%)

$$
\begin{array}{r}
24(80) \\
3(10) \\
3(10) \\
20(67) \\
10(33) \\
8(27) \\
12(40) \\
10(33)
\end{array}
$$

${ }^{\text {a}}$ Five pantries did not report pounds of food distributed in the past month.

Notes: A single building pantry was considered a location where the food pantry operated out of permanent space that did not change addresses from month to month and was not located within a school. Urbanicity was characterized by the food pantry agency as being in a zip code with a population density $>50,000$ people in 2010 census data. 
Table 2. Reliability Coefficients for Scored Items of Healthy Food Pantry Assessment Tool Sections A-E

Same Rater

\section{Field Test Item ( $\mathbf{n}=\mathbf{3 0}$ Sites)}

Section A: Location and entrance Average Section A

Walkability, pedestrian access

Bus access

Handicap access

Automobile access

Visual appeal

Location signage

Check-in type, first-time clients

Check-in type, returning clients

Wait time

Waiting location

Section B: Foods available to clients

Average Section B

Garden or farmers' market

Distribution model

Accessibility: convenience, order of foods

Accessibility: convenience, eye level, easy to reach ${ }^{a}$

Accessibility: appeal $^{\mathrm{a}}$

Salience: visual prompts, nutritional benefits

Fresh fruit availability

Fresh fruit variety

Fresh fruit quality ${ }^{a}$

Fresh vegetable availability

Fresh vegetable variety

Fresh vegetable quality ${ }^{a}$

Frozen fruit and vegetable variety

Frozen fruit and vegetable quality

Frozen lean protein variety

Frozen lean protein quality

Variety of canned foods

Quality of canned foods ${ }^{a}$

Low-sodium canned food availability

Low-sugar canned food availability

Low-fat dairy variety

Availability of eggs

Availability of legumes

Variety of grain items

Availability of whole-grain items

Section C: Policies of pantry

Average Section C

Guidelines for food accepted

Guidelines for food distributed

Documentation of respect policy

Display of respect policy

Food safety training for staff

Food safety training for volunteers

Surveys 1 and 2
( $n=56$
Matched Pairs)
Test-Retest
(Pearson $r$ )

.85

.85

.96

.70

1.00

.59

.93

.91

.86

.77

.83

.65

.88

.95

.78

.69

.62

.75

.59

.73

NS

.76

.68

.46

.55

.69

.40

.62

.80

.57

.69

.55

.63

.87

.60

.49

.53

.83

.86

.67

.92

.77

.92

.77

Between Raters

\section{Surveys 1 and 2 ( $n=56$ Matched \\ Pairs) \\ Interrater \\ (Pearson $r$ )}

\section{Survey 1 Only ( $\mathrm{n}=\mathbf{3 0}$ Matched \\ Pairs \\ Interrater (Intraclass \\ Correlation Coefficient)}

$\begin{array}{rr}.77 & 0.76 \\ .55 & 0.43 \\ .97 & 1.00 \\ .49 & 0.45 \\ 1.00 & 1.00 \\ .28 & 0.36 \\ .83 & 0.86 \\ .83 & 0.91 \\ .88 & 0.89 \\ .89 & 0.94 \\ .79 & 0.73 \\ & \end{array}$

0.63

0.85

0.96

0.72

$0.00^{\mathrm{b}}$

$0.24^{\mathrm{b}}$

0.78

0.77

0.69

$-0.01^{\mathrm{b}}$

0.77

0.69

$0.13^{\mathrm{b}}$

0.87

0.64

0.76

0.33

0.84

$-0.04^{\mathrm{b}}$

0.81

0.64

0.88

0.92

0.90

0.84

0.64

0.81

0.84

0.83

1.00

0.77

0.84

0.56 


\begin{tabular}{|c|c|c|c|}
\hline \multirow[b]{2}{*}{ Field Test Item ( $n=30$ Sites) } & \multirow{2}{*}{$\begin{array}{c}\text { Same Rater } \\
\text { Surveys } 1 \text { and } 2 \\
(n=56 \\
\text { Matched Pairs) } \\
\text { Test-Retest } \\
\text { (Pearson } r)\end{array}$} & \multicolumn{2}{|c|}{ Between Raters } \\
\hline & & $\begin{array}{c}\text { Surveys } 1 \text { and } 2 \\
\text { ( } \mathrm{n}=56 \text { Matched } \\
\text { Pairs) } \\
\text { Interrater } \\
\text { (Pearson } r)\end{array}$ & $\begin{array}{c}\text { Survey 1 Only } \\
\text { ( } n=30 \text { Matched } \\
\text { Pairs } \\
\text { Interrater (Intraclass } \\
\text { Correlation Coefficient) }\end{array}$ \\
\hline \multicolumn{4}{|c|}{ Section D: Food storage and safety (scored items only) } \\
\hline Average Section D & .80 & .73 & 0.77 \\
\hline Frozen storage available & .89 & .82 & 0.79 \\
\hline Chilled storage available & 1.00 & 1.00 & 1.00 \\
\hline Thermometer in dry storage & .69 & .87 & 0.86 \\
\hline Temperature in dry storage & NS & 1.00 & LR \\
\hline Handwashing signs & .78 & .84 & 0.86 \\
\hline Cleanliness $^{a}$ & .70 & .24 & $0.27^{b}$ \\
\hline Food transportation & .96 & .96 & 0.97 \\
\hline Pest management & .34 & .38 & 0.62 \\
\hline \multicolumn{4}{|l|}{ Section E: Services } \\
\hline Average Section E & .91 & .85 & 0.79 \\
\hline Nutrition education available (classes) & .85 & .81 & 0.72 \\
\hline Food demonstrations, recipes, or samples & .84 & .86 & 0.85 \\
\hline Other social service referral & .89 & .87 & 0.79 \\
\hline
\end{tabular}

LR indicates low response; NS, not significant.

All correlations were significant at $P<.05$ unless noted.

${ }^{a}$ Indicates questions with skip logic and fewer than 30 matched pairs, therefore intraclass correlation coefficient (ICC) calculation is not recommended; ${ }^{b}$ Indicates that the ICC value was not statistically significant $(P>.05)$.

question measuring handicap access was reworded to reflect accessibility by all persons. The questions regarding wait time and wait location were reordered to reflect the true movement of clients through a pantry. The visual appeal of the building question had a reverse scale that was corrected and an additional detail about frozen protein was added. The scales of questions related to the variety of grains, legumes, and whole grains were updated to keep a consistent scale throughout section $B$. The questions about the variety and quality of canned foods were skewed to the right and removed because they did not inform differences between pantries. Initial review of the submitted surveys $(n=172)$ of phase 4 revealed that respondents struggled with the graphic design by incorrectly completing question items. Data were coded to reflect a

Table 3. Reliability Coefficients for Non-scored Items of Healthy Food Pantry Assessment Tool Section F

\section{Field Test Item}

Section F: Supplementary Programs

Average Section $F$

Backpack program

Federal Child Nutrition Program

Registered Dietitian volunteer

Nutritional training

Mobile or school pantry

Home delivery

Hot meals

Special dietary needs foods

Volunteer appreciation
Same Rater

$\begin{array}{ccc}\text { Surveys } 1 \text { and } 2 & \text { Surveys } 1 \text { and } 2 \\ (\mathrm{n}=56 \text { Matched Pairs) } & (\mathrm{n}=56 \text { Matched Pairs) } \\ \text { Test-Retest } & \text { Interrater } \\ \text { (Pearson } r \text { ) } & \text { (Pearson } r \text { ) }\end{array}$

$\begin{array}{rrr}.85 & .81 & 0.77 \\ .89 & .79 & 0.64 \\ 1.00 & .79 & 0.72 \\ 1.00 & .92 & 0.90 \\ .83 & .83 & 0.82 \\ .66 & .73 & 0.75 \\ .87 & .86 & 0.75 \\ 1.00 & 1.00 & 1.00 \\ 1.00 & .72 & 0.75 \\ .71 & .62 & 0.56\end{array}$

Between Raters

Survey 1 Only
( $\mathrm{n}=\mathbf{3 0}$ Matched Pairs)
Interrater

All correlations were significant at $P<.05$. 
Pearson $r$

\section{Survey Item}

Accessibility: convenience, order of foods ${ }^{a}$

Accessibility: convenience, eye level, easy to reach ${ }^{a}$

Accessibility: appeal ${ }^{\mathrm{a}}$

Fresh fruit variety

Fresh vegetable variety

Fresh vegetable quality

Frozen fruit and vegetable quality

Display of respect policy

Temperature in dry storage ${ }^{a}$

Frequency (\%)
$50(29)$
$49(28)$
$50(29)$
$12(6.9)$
$15(9.7)$
$13(7.5)$
$22(13)$
$21(12)$
$37(22)$

Frequency (\%)

$50(29)$

$49(28)$

$12(6.9)$

$15(9.7)$

$13(7.5)$

$21(12)$

37 (22)

\begin{tabular}{cc}
\hline \multicolumn{2}{c}{ Pearson $\mathbf{r}$} \\
Test-Retest $(\mathbf{n = 5 6 )}$ & Interrater $(\mathbf{n = 8 1 )}$ \\
.78 & .53 \\
.69 & .48 \\
.62 & .66 \\
.73 & .85 \\
.68 & .82 \\
.46 & .44 \\
.69 & .56 \\
.77 & .73 \\
.16 & 1.00
\end{tabular}

${ }^{a}$ Indicates that the graphic design of the question was updated in the final survey.

$\mathrm{n}=172$ submitted surveys. All correlations were significant at $P<.05$.

failure of skip logic and the percentage of respondents incorrectly answering questions was calculated. Edits were considered if $>5 \%$ of surveys in that question item were returned with mistakes and if 1 of the 2 correlations was $<0.60$ (Table 4 ). For instance, the faulty skip logic interpreted similarly across time points and between users would result in higher correlations and incorrect survey logic application, as was the case with the 3 accessibility questions.

\section{Cognitive Retesting With Subsample}

Additional changes to the layout and question details were made after cognitive testing of a subset of field test participants $(n=10)$ to improve the survey. Final edits included clarification of client choice in the food distribution model question, improvement in the skip logic design, and expansion of the response options for the variety of legumes and types of eggs. The final HFPAT had a Flesch-Kincaid reading level of 8.7 and 69 total questions. ${ }^{52}$

\section{DISCUSSION}

The HFPAT had appropriate face validity and demonstrated good reliability in a test of 30 different pantry agencies in 7 states. The reliability scores were substantial for the majority of HFPAT items, 48 items for testretest and 49 for interrater reliability, as indicated by Pearson correlation coefficients of $0.6-1.0$. Items with moderate or fair reliability were edited and items with poor reliability were removed. Differing perspectives of pantry representatives and community partner respondents may have contributed to the fair interrater reliability of items on frozen lean protein quality and pantry cleanliness. Interrater reliability may also have been affected by the bias of the respondents because pantry representatives might have viewed their environments more positively, thus scoring them higher than their external community partners. ${ }^{43}$

These results were comparable to those of other food environment escans. Glanz et al $^{30}$ tested their Nutrition Environment Measures Survey in Stores e-scan in 85 stores and reported high interrater and testretest reliability for food availability measures, with $\kappa$ values ranging from 0.84 to 1.00 and 0.73 to 1.00 , respectively; the quality of fresh produce had moderate reliability in the Nutrition Environment Measures Survey in Stores, indicated by $\kappa$ values of 0.44-1.00. Ghirardelli et $\mathrm{al}^{48}$ tested their CX3 food retail e-scan in 26 stores in low-income areas in California and reported good interrater reliability, with $\kappa$ scores ranging from 0.37 to 0.70 and ICC ranging from 0.47 to $0.89 .{ }^{49}$ Hosler and Dharssi ${ }^{53}$ tested their Food Retail Outlet Survey Tool e-scan in 39 urban stores in Albany, NY and reported high interrater reliability with $\kappa$ ranging from 0.59 to 1.00. The environments between food pantries and retail grocery stores might differ in the consumer type served, because pantries are designed to alleviate hunger in the community. It has been suggested that food pantry clients represent vulnerable consumers when they obtain food from pantries. ${ }^{25}$ However, many retail studies investigating healthy food availability and access focused on the same lowincome communities that were served by pantries. ${ }^{53-57}$ Previous retail store e-scan studies reported the need for standardized, validated tools to measure the healthfulness of community nutrition environments. ${ }^{15,30,49,53}$ To the authors' knowledge, this study led to the creation of a scored food pantry e-scan, the first to be tested across multiple states. The HFPAT may be applicable to a wider audience than might other tools tested in only 1 state. $^{33,34,48}$ A resource guide was developed to accompany the HFPAT to increase the usability of the survey in FPE interventions. Continuous cognitive testing with intended HFPAT users was completed during the third and fourth phases of the study. Overall, the high interrater and test-retest reliability indicated that the HFPAT generated consistent scores regardless of who completed the assessment.

This study relied on 3 convenience samples in which respondents were recruited through SNAP-Ed and EFNEP networks. Snowball sampling may generate a group of respondents who are more homogeneous compared with those in studies using other convenience sampling methods. This potentially limits the types of community partners who may seek 
to use the HFPAT because results reflect the perspectives of food pantry insiders and SNAP-Ed or EFNEP. The reliability of the HFPAT is limited by the sample size and the seasonality of food available to pantries. Testretest reliability was determined over 14 days and some pantry environments may have shifted during this time, especially during a period of high need such as the holidays. Ranking of content by a formal expert panel was not conducted. Questions were removed and wording and design were revised in the final adaptation of the HFPAT, which merits future reliability testing. The HFPAT is limited by a lack of criterion validity. Many environmental assessments lack validity owing to a missing standard to compare observable changes. ${ }^{58}$ Laboratory settings for food pantry clients were recommended to test other effects of environment on consumer food behavior because the pantry provides a unique setting in which money is not exchanged for goods. ${ }^{25}$

\section{IMPLICATIONS FOR RESEARCH AND PRACTICE}

Future research might evaluate the content validity of the HFPAT in an adapted content validity index suggested by Lynn. ${ }^{59}$ Further evaluations might assess the use of this tool for the Healthy Eating Index related to inventory, client take-home, and diet quality.

Public health interventions require valid and sensitive tools to measure the effectiveness of environmental interventions in a wide range of community nutrition settings. The HFPAT, a tool for the food assistance setting, was designed as a comprehensive assessment of the physical and emotional space within the pantry and the nutritional quality of the food offered. The tool can be completed by the pantry staff or a community partner in consultation with the pantry. The results can focus community coaching from SNAP-Ed, EFNEP, or other extension or public health professionals to support pantry change. A readiness tool may complement the environmental assessment of food pantries. ${ }^{60}$ Testers of the
HFPAT described using their scores to report changes through the SNAP-Ed Evaluation Framework. ${ }^{61}$ This survey demonstrated a satisfactory level of test-retest and interrater reliability. Results were consistent with food retail e-scan research. ${ }^{30,48,53}$ This study resulted in the creation of a multicomponent toolkit containing the HFPAT, instruction guide, resource guide, and training webinar. The toolkit can be used in FPEs to generate numeric scores that allow pantries and their community partners to identify areas for improvement and evaluate the effectiveness of interventions. The final survey, containing 61 scored items and 8 descriptive questions, was formatted to print as a booklet and is available for download. ${ }^{62}$ Additional research might evaluate criterion validity and how food panty environment changes affect the diet quality of their clients.

\section{ACKNOWLEDGMENTS}

This project was supported by the Regional Nutrition Education and Obesity Prevention Center of Excellence Initiative of the US Department of Agriculture, National Institute of Food and Agriculture, Grant No. 2014-48757-22607. The authors wish to acknowledge the Center for Interdisciplinary Statistics Education and Research at Washington State University for the statistical analysis of field test data.

\section{REFERENCES}

1. Coleman-Jensen A, Rabbitt MP, Gregory CA, Singh A. Household Food Security in the United States in 2016. Washington, DC: Economic Research Service, US Department of Agriculture; 2017.

2. Weinfield N, Gregory M, Borger C, Gearing M, Macaluso T, Montaquila J, Zedlewski S. Hunger in America 2014: National Report Prepared for Feeding America. Washington, DC: Urban Institute; 2014.

3. Seligman HK, Laraia BA, Kushel MB. Food insecurity is associated with chronic disease among low-income NHANES participants. J Nutr. 2010; 140:304-310.

4. Remley DT, Kaiser ML, Osso T. A case study of promoting nutrition and long- term food security through choice pantry development. J Hunger Environ Nutr. 2013;8:324-336.

5. Campbell EC, Ross M, Webb K. Improving the nutritional quality of emergency food: a study of food bank organizational culture, capacity, and practices. J Hunger Environ Nutr. 2013; 8:261-280

6. Verpy H, Smith C, Reicks M. Attitudes and behaviors of food donors and perceived needs and wants of food shelf clients. J Nutr Educ Behav. 2003;35:6-15.

7. Duffy P, Zizza C, Jacoby J, Tayie FA. Diet quality is low among female food pantry clients in Eastern Alabama. J Nutr Educ Behav. 2009;41:414-419.

8. Simmet A, Depa J, Tinnemann P, Stroebele-Benschop N. The dietary quality of food pantry users: a systematic review of existing literature. J Acad Nutr Diet. 2017;117:563-576.

9. Office of Disease Prevention and Health Promotion. Dietary Guidelines for Americans: 2015-2020. 8th ed. US Department of Healthy and Human Services and US Department of Agriculture. http://www.health. gov/dietaryguidelines/2015/guidelines. Accessed April 12, 2018.

10. Campbell E, Hudson H, Webb K, Crawford PB. Food preferences of users of the emergency food system. J Hunger Environ Nutr. 2011;6:179-187.

11. Dave JM, Thompson DI, SvendsenSanchez A, McNeill LH, Jibaja-Weiss M. Development of a nutrition education intervention for food bank clients. Health Promot Pract. 2017;18:221-228.

12. Drewnowski A, Specter S. Poverty and obesity: the role of energy density and energy costs. Am J Clin Nutr. 2004;79:6-16.

13. Drewnowski A, Eichelsdoerfer P. Can low-income Americans afford a healthy diet? Nutr Today. 2009;44:246-249.

14. Mulik K, Haynes-Maslow L. The affordability of MyPlate: an analysis of SNAP benefits and the actual cost of eating according to the dietary guidelines. J Nutr Educ Behav. 2017;49:623-631.

15. Glanz K, Sallis JF, Saelens BE, Frank LD. Healthy nutrition environments: concepts and measures. Am J Health Promot. 2005;19:330-333.

16. Sallis JF, Glanz K. Physical activity and food environments: solutions to the obesity epidemic. Milbank Q. 2009;87:123-154.

17. Story M, Kaphingst KM, RobinsonO'Brien R, Glanz K. Creating healthy food and eating environments: policy 
and environmental approaches. Annu Rev Public Health. 2008;29:253-272.

18. Smith C, Morton LW. Rural food deserts: low-income perspectives on food access in Minnesota and Iowa J Nutr Educ Behav. 2009;41:176-187.

19. Smith C, Miller H. Accessing the food systems in urban and rural Minnesotan communities. J Nutr Educ Behav. 2011; 43:492-504.

20. Bowen DJ, Barrington WE, Beresford SA. Identifying the effects of environmental and policy change interventions on healthy eating. Annu Rev Public Health 2015;36:289-306

21. Byker Shanks C. Promoting food pantry environments that encourage nutritious eating behaviors. J Acad Nutr Diet. 2017;117:523-525.

22. Vissing Y, Gu J, Jones A, Gabriel S. Preserving dignity in the face of hunger: a study of food pantry utilization. Humanity Soc. 2017;41:461-481.

23. Daponte BO. Private versus public relief: use of food pantries versus food stamps among poor households. J Nutr Educ. 2000;32:72-83.

24. Molnar J, et al. Private food assistance in a small metropolitan area: urban resources and rural needs. $J$ Sociol Soc Welf. 2001;28:187-209.

25. Wilson N. When the cupboards are bare: nudging food pantry clients to healthier foods. J Assoc Consum Res. 2016;1:125-133.

26. Martin KS, et al. A novel food pantry program: food security, self-sufficiency, and diet-quality outcomes. Am J Prev Med. 2013;45:569-575.

27. Wansink B. From mindless eating to mindlessly eating better. Physiol Behav. 2010;100:454-463.

28. Wilson NLW, Just DR, Swigert J, Wansink B. Food pantry selection solutions: a randomized controlled trial in client-choice food pantries to nudge clients to targeted foods. J Public Health (Oxf). 2017;39:366-372.

29. Saelens BE, Glanz K, Sallis JF, Frank LD. Nutrition environment measures study in restaurants (NEMS-R): development and evaluation. Am J Prev Med. 2007;32:273-281.

30. Glanz K, Sallis JF, Saelens BE, Frank LD. Nutrition environment measures survey in stores (NEMS-S): development and evaluation. Am J Prev Med. 2007;32:282-289.

31. McKinnon R, Reedy J, Morrissette MA, Lytle LA, Yaroch AL. Measures of the food environment: a compilation of the literature, 1990-2007. Am J Prev Med. 2009;36(4 suppl):S124-S133.

32. Glanz K, Johnson L, Yaroch AL, Phillips M, Ayala GX, Davis EL. Measures of retail food store environments and sales: review and implications for healthy eating initiatives. J Nutr Educ Behav. 2016;48:280-288.

33. Canto A, Ingham $\mathrm{B}$, Larson $\mathrm{S}$. Safe \& Healthy Food Pantries Project. Madison, WI: University of WisconsinExtension; 2015.

34. Turner J, Shapiro-Shellaby M, Weaver E, Streit K, Quinn M. Healthy Pantry Initiative Strategies for Encouraging Healthy Choices at the Pantry. Portland, OR: Oregon Food Bank; 2011.

35. California Department of Public Health. CX3-NF6 Tier 2 Emergency Food Outlet Survey. Communities of Excellence in Nutrition, Physical Activity and Obesity Prevention. Sacramento, CA: California Department of Public Health; 2013.

36. Nikolaus CJ, Laurent E, Loehmer E, An R, Khan N, McCaffrey J. Nutrition environment food pantry assessment tool (NEFPAT): development and evaluation. J Nutr Educ Behav. 2018;50: 724-728.e1.

37. Greater Chicago Food Depository. Pantry Needs and Capacity Self-Assessment for GCFD Pantries. Chicago, IL: Greater Chicago Food Depository; 2012.

38. Maziarz T, Abodeely A. 4-Star Food Pantry Model: Creating Healthier Food Pantries Together in Northwest Ohio. Toledo, OH: Toledo-Lucas County Health Department; 2014.

39. Friese S. Qualitative Data Analysis With ATLAS.ti. London, UK: Sage; 2012:134-135

40. Handforth B, Hennink M, Schwartz MB. A qualitative study of nutrition-based initiatives at selected food banks in the Feeding America Network. J Acad Nutr Diet. 2013;113:411-415.

41. Leung CW, Hoffnagle EE, Lindsay AC, Lofink HE, Hoffman VA, Turrell S, et al. A qualitative study of diverse experts' views about barriers and strategies to improve the diets and health of Supplemental Nutrition Assistance Program (SNAP) beneficiaries. J Acad Nutr Diet. 2013;113:70-76.

42. Dillman D, Smyth J, Christian L. Internet, Mail, and Mixed-Mode Surveys: The Tailored Design Method. 3rd ed. Hoboken, NJ: Wiley \& Sons; 2009:65-106.
43. Nunnally JC, Bernstein I. Psychometric Theory. 3rd ed. New York, NY: McGrawHill; 1994:251-256.

44. Koo TK, Li MY. A guideline of selecting and reporting intraclass correlation coefficients for reliability research. J Chiropr Med. 2016;15:155-163.

45. Sim J, Wright CC. The kappa statistic in reliability studies: use, interpretation, and sample size requirements. Phys Ther. 2005;85:257-268.

46. Landis JR, Koch G. The measurement of observer agreement for categorical data. Biometrics. 1977;33:159-174.

47. Guthrie JF. Integrating behavioral economics into nutrition education research and practice. J Nutr Educ Behav. 2017;49:700-705.

48. Ghirardelli A, Quinn V, Sugerman S. Reliability of a retail food store survey and development of an accompanying retail scoring system to communicate survey findings and identify vendors for healthful food and marketing initiatives. J Nutr Educ Behav. 2011;43:S104-S112.

49. Pedestrian and Bicycle Information Center. Walkability checklist. http://www. pedbikeinfo.org/community/walkability. cfm. Accessed July 6, 2018.

50. National Restaurant Association Educational Foundation. ServSafe Coursebook. 5th ed. Chicago, IL: National Restaurant Association Educational Foundation; 2010.

51. Davis LB, Sengul I, Ivy JS, Brock III LG, et al. Scheduling food bank collections and deliveries to ensure food safety and improve access. Socioecon Plann Sci. 2014;48:175-188.

52. Kincaid JP, Fishburne RP Jr, Rogers RL, Chissom BS. Derivation of New Readability Formulas (Automated Readability Index, Fog Count and Flesch Reading Ease Formula) for Navy Enlisted Personnel. Accession Number ASA006655. Fort Belvoir, VA: Defense Technical Information Center, US Department of Defense; 1975.

53. Hosler AS, Dharssi A. Reliability of a survey tool for measuring consumer nutrition environment in urban food stores. J Public Health Manag Pract. 2011;17:E1-E8

54. Rose DR. Food store access and household fruit and vegetable use among participants in the US Food Stamp Program. Public Health Nutr. 2004;7: 1081-1088.

55. Jilcott SB, Laraia BA, Evenson KR, Ammerman AS. Perceptions of the 
community food environment and related influences on food choice among midlife women residing in rural and urban areas: a qualitative analysis. Women Health. 2009;49:164-180.

56. Webber CB, Sobal J, Dollahite JS. Shopping for fruits and vegetables: food and retail qualities of importance to low-income households at the grocery store. Appetite. 2010;54:297-303.

57. Wetherill MS, Gray KA. Farmers' markets and the local food environment: identifying perceived accessibility barriers for snap consumers receiving
Temporary Assistance for Needy Families (TANF) in an urban Oklahoma community. J Nutr Educ Behav. 2015; 47:127-133.

58. Lytle LA. Measuring the food environment: state of the science. Am J Prev Med. 2009;36:S134-S144.

59. Lynn MR. Determination and quantification of content validity. Nurs Res. 1986;35:382-385.

60. Butel JA, Banna JC, Novotny R, Franck KL, Parker SP, Stephenson L. Validation of a collaboration readiness assessment tool for use by
Supplemental Nutrition Assistance Program -Education (SNAP-Ed) agencies and partners. J Nutr Educ Behav. 2018;50:501-505.

61. US Department of Agriculture. SNAP-Ed Evaluation Framework and Interpretive Guide. Washington, DC: US Department of Agriculture; 2016.

62. Bush-Kaufman A. Healthy Food Pantry Assessment Toolkit. Tacoma, WA: Washington State University Extension, Pierce County Website; 2018.

\section{Panel on H index / Impact Factor - Cornerstone of Your Career at the SNEB Annual Conference}

The panel of JNEB editors will describe the h-index and other metrics that relate to research impact and career development. The Impact Factor and other journal metrics will be explored and discussed:

Learning Objectives:

- Will understand h-indices and how this related to their career

- Will understand Impact Factors and how this related to their research

- Will understand how to improve their h-index

https: / / events.resultsathand.com/sneb2019/888/agenda.html\#session/29139 